\title{
"COMO SEI QUE EU SOU EU?" CINESTESIA E ESPACIALIDADE NAS CONFERÊNCIAS HUSSERLIANAS DE 1907 E EM PESQUISAS NEUROCOGNITIVAS ${ }^{1}$
}

\author{
How do I Know That I am Myself? - Kinesthesia and Spatiality in the Husserlian \\ Conferences of 1907 and in Neurocognitive Research \\ ¿Cómo Puedo Saber que Soy Yo? - Cinestesia y Espacialidad en las Conferencias \\ Husserlianas de 1907 y en Investigaciones Neurocognitivas
}

Thiago Gomes de Castro

WiLliam Barbosa Gomes

\begin{abstract}
Resumo: Husserl definiu cinestesia como a experiência vivida e autoconsciente do movimento e do gesto, associada à unidade corporal, ao desenvolvimento do esquema do ego estendido, e à percepção de espaço. O estudo contrasta dificuldades históricas e colaborações recentes entre fenomenologia e pesquisa experimental. A análise sustenta-se na revisão de estudos clássicos sobre cinestesia e percepção, e em pesquisas neurocognitivas recentes, destacando as implicações para a compreensão da intencionalidade. O conceito de cinestesia refere-se a duas questões fenomenológicas: como sei que eu sou eu, e quem sou eu. O senso de si e da ação presente passam pela integração da consciência reflexiva no desempenho motor e perceptivo, conforme confirmam experimentos fenomenológicos e neurocognitivos sobre situações de ambiguidade proprioceptiva. Tais estudos estão abrindo novas possibilidades para reabilitação de desordens proprioceptivas - como no caso de amputação, comorbidades de auto-imagem e mesmo esquizofrenia - e para colaborações profícuas entre fenomenologia e neurociências cognitivas.
\end{abstract}

Palavras-chave: Cinestesia; Autoconsciência; Intencionalidade; Fenomenologia; Neurocognição.

Abstract: Husserl defined kinesthesia as the self-consciousness lived experience of movement and gesture, associated to the body unity, to the development of an extended ego schema, and to spatial perception. The study contrasts historical difficulties and recent collaborations between phenomenology and experimental research. The analysis is sustained in classical studies review on kinesthesia and perception, and in recent neurocognitive research, emphasizing implications to an understanding of intentionality. The concept of kinesthesia refers to two phenomenological issues: How do I know that I am myself, and who am I. The sense of self and actual action passes through the integration of reflective consciousness in motor action and perception, as confirmed by phenomenological and neurocognitive experiments using proprioceptive ambiguity contexts. Those studies are opening new possibilities to the rehabilitation of proprioceptive disorders - as in the case of amputees, self-image comorbidities and schizophrenia - and also to fruitful collaborations between phenomenology and cognitive neurosciences.

Keywords: Kinesthesia; Selfconsciousness; Intentionality; Phenomenology; Neurocognition.

Resumen: Husserl define cinestesia como la auto-conciencia de la experiencia vivida del movimiento y el gesto, asociado a la unidad del cuerpo, a lo desarrollo de un esquema de ego extendido, y a la percepción espacial. El estudio contrasta las dificultades históricas y recientes colaboraciones entre la fenomenología y la investigación experimental. El análisis se sustenta en la revisión de estudios clásicos en cinestesia y la percepción, y en la investigación neurocognitiva reciente, destacando las implicaciones para la comprensión de la intencionalidad. El concepto de cinestesia se refiere a dos aspectos fenomenológicos: Cómo puedo saber que soy yo, y que yo soy. El sentido de sí mismo y la acción propia pasa por la integración de la conciencia reflexiva en la acción motora, según lo confirmado por experimentos fenomenológicos y neurocognitivos utilizando contextos de ambigüedad propioceptiva. Estos estudios están abriendo nuevas posibilidades para la rehabilitación de los trastornos propioceptivos - como en el caso de los amputados, comorbilidades de imagen de sí mismo y la esquizofrenia - y también a la colaboración fructífera entre la fenomenología y las neurociencias cognitivas.

Palabras-clabe: Cinestesia; Auto-consciencia. Intencionalidad; Fenomenología; Neurocognición.

Palestra proferida pelo primeiro autor no II Congresso Sul-Brasileiro de Fenomenologia \& II Congresso de Estudos Fenomenológicos do Paraná, realizado na UFPR, em Curitiba, de 03 a 04 de junho de 2011. 


\section{Introdução}

O presente artigo discute a articulação entre os conceitos de cinestesia e espacialidade no texto husserliano intitulado Dingvorlesung (Thing and Space - Lectures of 1907) e a relação com estudos de psicologia experimental, de diferentes períodos históricos, que investigaram os mesmo processos. O texto está organizado em quatro partes. Primeiro, apresenta breve descrição do contexto histórico e das características do texto de Husserl de 1907. Segundo, discute as definições de cinestesia e espacialidade em Husserl, destacando a importância dada à mediação autoconsciente. Terceiro, contrasta a definição de percepção espacial de três pesquisadores experimentais David Katz, James J. Gibson e Alva Nöe - com a definição husserliana. Por fim, traz resultados de pesquisas recentes com correlatos neurais em tarefas experimentais na percepção de movimento e propriocepção espacial para rediscutir a versão husserliana de cinestesia.

\section{Cinestesia e Contexto Histórico de Husserl em 1907}

O tema da Cinestesia em Husserl aparece com maior detalhamento em uma série de conferências proferidas em 1907, quando Husserl lecionava na Universidade de Göttingen na Alemanha. O texto de 1907 refere-se à transcrição de um curso oferecido naquela Universidade, sendo que apenas parte dessas conferências foi traduzida para o português, com o título A Idéia da Fenomenologia (1907/2000). Nesse breve texto são apresentadas cinco conferências introdutórias do curso de Husserl, mas são relativamente independentes do seguimento das palestras descritas em Thing and Space. Na Idéia da Fenomenologia Husserl enfocará a descrição do método das reduções fenomenológicas. Já em Thing and Space o escopo das análises tratará basicamente da construção da espacialidade, com ênfase na cinestesia. Vale lembrar que em 1905 Husserl já havia se detido à discussão da consciência interna do tempo, e agora espaço e tempo se fundirão para uma compreensão ampliada da experiência intencional.

Sabe-se que entre a audiência do curso de 1907 estava Georg Elias Müller (1850-1934), chefe da cadeira de psicologia experimental da Universidade de Göttingen (Ash, 1995). Nesse momento, Müller já havia estabelecido um programa de psicologia experimental que buscava fundamentação na fenomenologia, dedicando-se principalmente à investigação empírica da memória. O sentido fenomenológico adotado por G.E.Müller foi o da fenomenologia como psicologia descritiva, associado à transposição metodológica da fenomenologia de Husserl. Spiegelberg
(1972) relata, contudo, que Husserl não aprovava o uso da fenomenologia conforme Müller e o departamento de psicologia de Göttingen. De seu lado, Müller considerava a resistência de Husserl em relação às inovações empíricas como um isolamento não produtivo e que sua forma de filosofar era um preciosismo verbal.

Mesmo assim, ao contrário do laboratório de Leipzig, em Göttingen a nova teoria fenomenológica na experimentação procurava distanciar as teses elementaristas e fisicalistas sobre o funcionamento da consciência. Wundt e os psicólogos de Leipzig são inclusive criticados em Thing and Space por Husserl no tocante à questão da distinção entre percepção e apercepção. Como se sabe, o termo perсерс̧ão refere-se ao processo de conhecimento de objetos e eventos por meios sensoriais. Em contraste, o termo apercepção, de Leibniz a Wundt, foi entendido como o processo no qual o conteúdo era focalizado mais claramente para a compreensão, posterior à percepção (Klein, 1970). A insistência de Husserl (1907/1997), no entanto, é enfatizar a percepção como processo ativo vinculado à intencionalidade. $\mathrm{O}$ entendimento da época para apercepção sugeria certa passividade e independência entre percepção e intencionalidade. Segundo o filósofo, tal entendimento passivo da apercepção teria sido suplantado pelo conceito de apreensão de Carl Stumpf (1848-1936). De acordo com Husserl, Stumpf entende que a ideia de apercepção seria insuficiente dentro de uma compreensão intencional da percepção, sendo mais adequado falar de um modo particular do organismo no acesso a evidência como apreensão ativa das coisas. Similar a essa proposição ativa de Stumpf é o conceito de intencionalidade operante de Husserl (Husserl, 1913/2006).

Em 1907, Carl Stumpf coordenava o laboratório de psicologia da Universidade de Berlim, onde orientava as teses de doutorado de dois dos fundadores da Psicologia da Gestalt: Kurt Koffka (1886-1941) e Wolfgang Köhler (18871967). No entanto, o interesse de Stumpf pela fenomenologia começava a declinar em 1907, uma vez que Husserl buscava, há algum tempo, afirmar a fenomenologia como ciência primeira e com um método filosófico próprio para tal empreitada. Assim como G.E.Müller, Stumpf não via com bons olhos o excessivo afastamento de Husserl da investigação empírica, exatamente por este defender uma via puramente teórica à intencionalidade.

Também entre os ouvintes das conferências de 1907, estava o orientando de Husserl em Göttingen, Wilhelm Schapp (1884-1965), que realizou uma análise intencional filosófica da percepção de cores. Na mesma época, o psicólogo Oswald Külpe (1862-1915), aluno de Wündt, buscava desenvolver um programa de psicologia experimental na Universidade de Würzburg, baseado em uma fenomenologia descritiva e entendida como ciência de realidades (Spiegelberg, 1972). Külpe foi o orientador da tese de Max Wertheimer (1880-1943), outro cofundador da Psicologia da Gestalt, também na década de 1900. Acompanhando Müller e Stumpf, Külpe mantinha res- 
trições à direção da filosofia fenomenológica delineada por Husserl, considerando-a importante, mas metodologicamente imperfeita no tratamento da realidade. Schapp e Külpe são dois exemplos de autores influenciados por Husserl nesse período, mas que seguiram por caminhos distintos no estudo da percepção, o primeiro para a análise eidética e o segundo para a análise descritiva, empírica e rigorosa.

Ainda que notórias as diferenças de propósito entre Husserl e os psicólogos alemães da década de 1900, percebe-se entre os autores uma forte tendência de combate às teses psicofísicas vigentes nesse momento. Enquanto Husserl fazia esforços para suplantar a epistemologia das investigações baseadas no sensorialismo, alguns psicólogos enfrentavam o desafio de criar condições experimentais e leis de interpretação diferenciadas, na direção de uma lógica descritiva fenomenológica. Nesse momento, o destaque que Husserl confere à cinestesia para a percepção mantém conexão com as modalidades inovadoras de pesquisa de percepção espacial que os discípulos de Müller, Külpe e Stumpf irão desenvolver nas décadas seguintes. Vejamos como Husserl define cinestesia.

\section{2. “Como sei que eu sou eu?" - Cinestesia e Espa- cialidade em Husserl}

Em um sentido genérico, o termo Cinestesia é composto por dois radicais, "Cine" que significa movimento e "Estesia" que indica sensação ou percepção. Cinestesia, portanto, seria uma sensação ou percepção de movimento. Cinestesia é diferente de Sinestesia, que significa a relação de planos sensoriais distintos como, por exemplo, olfato e visão. O termo "sinestesia" é empregado na neurologia como uma união sensória involuntária em que a informação real de um sentido é acompanhada por uma percepção em outro sentido não estimulado (Hubbard \& Ramachandran, 2005). Por exemplo, o indivíduo é estimulado por uma cor azul, como o céu azul, e sente ao mesmo tempo o cheiro de um morango, que não está presente no contexto de estimulação. Há também uma tendência em se considerar cinestesia como sinônimo de propriocepção. Contudo, embora semelhantes, os dois termos guardam diferenças sutis. A propriocepção englobaria um sentido mais conceitual e integrativo da percepção, associado ao senso de equilíbrio corporal, mas não necessariamente à ênfase no senso de movimento como na cinestesia.

A cinestesia está associada a um senso espacial corporal interno e externo, sendo a dimensão externa associada ao conceito denominado peri-espaço, que seria o espaço não corporal logo em torno do corpo e que faz parte de um sistema de esquema corporal ligado à sensação de movimentos (Cardinali, Brozzoli \& Farnè, 2009). O senso interno estaria associado à interação entre canais sensoriais básicos no corpo para a sensação de mo- vimento. Ambos, sensos interno e externo, indicam uma integração primária com o sistema sensorial vestibular, localizado no ouvido interno.

Para Husserl (1907/1997), a cinestesia designa a experiência vivida da postura corporal, isto é, a orientação dos órgãos motores da percepção em movimento, incluindo os atos usados para simular esses movimentos na consciência. A sensação de movimento é o fenômeno puro na constituição da espacialidade. A constituição dos membros como conteúdos físicos aparentes no campo visual precede a noção de unidade do corpo (Husserl, 1931³ , citado por Petit, 2010). As dinâmicas cinestésicas remetem aos impulsos instintuais nos bebês, nos fenômenos da orientação da visão e na projeção das mãos em direção a um objeto de interesse (Husserl, 1907/1997).

$\mathrm{O}$ ato em movimento está alocado na teoria da constituição de Husserl. Por constituição fenomenológica entende-se o ato pelo qual um objeto surge ou configurase na consciência, cuja característica mais fundamental na cinestesia é a autoconsciência do sujeito na ação ("eu estou fazendo"). $\mathrm{O}$ ato tem o significado de uma autoconsciência ativa por todo o período em que persiste sua execução (Husserl, 1907/1997). Portanto, trata-se para Husserl de uma vigília concomitante da constituição do ato e da consciência de estar desempenhando este ato. Daí deriva a indagação que dá o título a essa exposição: Como sei que eu sou eu? Nas conferências de 1907, a cinestesia está associada à necessidade de uma concomitância autoconsciente no desempenho da ação, especialmente em vista do método descritivo de análise da intencionalidade, que repousa sobre o aspecto da experiência consciente.

Posteriormente, no texto Psicologia Fenomenológica, Husserl (1925/1977) relata que o estudo da intencionalidade e seus modos de acesso à evidência não se faz completo sem o correspondente intencional do corpo em sua função perceptiva. Segundo o autor, o corpo é, ao mesmo tempo, coisa (eidos) e função intencional (gênese). Uma análise do sistema cinestésico seria uma nova forma de análise da intencionalidade (Husserl, 1925/1977). Tanto no sentido eidético (estático), como em um sentido genético (processual), conforme indicado a seguir.

Schmicking (2010) reforça a idéia de Husserl ao situar a cinestesia como um dos aportes nas análises estática e genética da intencionalidade para a constituição dos objetos ou experiências. Junto com a incorporação, a cinestesia seria a referência para entender o acesso tipificado ou padronizado a novas experiências, como um modo intencional (Análise Estática). A cinestesia seria também uma via alternativa para compreender a auto-organização perceptiva no acesso a novas experiências ao longo de um fluxo temporal de vividos (Análise Genética). Em ambos os casos, ocorrem análises de estabilidade e de variações: na fenomenologia estática, procede-se uma

3 O Problema do Ato (1931) - Edmund Husserl 
análise de essências pelo traço perceptivo em um evento experiencial; na fenomenologia genética, procede-se uma análise de transições e constâncias da percepção em um fluxo temporal de vividos. Schmicking (2010) não menciona a análise generativa, que seria o modo de análise intencional sobre as conexões ecológicas dos atos. Ainda em 1907 nota-se também a ausência desta análise no texto de Husserl.

Em Husserl (1907/1997), a constituição recíproca do movimento de diferentes órgãos em um campo sensorial define a noção de espaço próprio e, por conseguinte, de um mesmo corpo (unidade egóica). Pergunta-se então: $\mathrm{O}$ que seria primordial na reunião desses diferentes movimentos? Aparentemente, a visão desponta como o recurso integrador do eu. Nesse texto, o sistema háptico, a participação músculo-esquelético em toques e contatos táteis é reconhecido como fundamental na integração, possivelmente como recurso concomitante à visão. Isto porque exerceria uma função diferente da visão, sendo a visão o pólo primário de identificação do movimento e o sistema háptico como pólo de sensação de continuidade temporal do movimento. O sistema táctil, decorrente do sistema háptico, aparece como recurso na extensão da unidade do ego para os movimentos externos à sensação de movimento corporal. Nesse ponto, o tema da cinestesia integra-se ao da experiência do mundo para a constituição de um esquema de ego estendido.

Os objetos intencionados que compõem a corporeidade estendida obviamente não possuem caracteres cinestésicos. Contudo, os objetos que estão no mundo participam do sistema auto-referente do corpo, este sim cinestésico (Husserl, 1931 citado por Petit, 2010). Isto significa que a sensação de movimento e a construção da espacialidade corpórea não englobariam a carne do mundo, como em Merleau-Ponty, mas os objetos do mundo são fundamentais para a dimensão auto-referente e autoconsciente do corpo em relação à percepção do mundo. Os objetos são parte do sistema cinestésico como utensílios ou pólo negativo, mas não como extensão carnal do movimento. Husserl discute em 1931 a relação do corpo com ferramentas que ampliam o sistema intencional de constituição auto-referente da espacialidade. O uso de ferramentas, como descrito em 1931, poderia ser uma saída em direção à via generativa, ecológica, não enfatizada nas conferências de 1907.

Observamos a importância dada por Husserl à dimensão autoconsciente na sensação de movimentos. O filósofo buscava com isso enfatizar o elemento operante da intencionalidade na construção de referentes espaciais no fluxo de vividos. Esse controle consciente da experiência do espaço não só serviria a um domínio da espacialidade, como também uma via para a análise de padrões intencionais na percepção do meio e na propriocepção. Com isso, Husserl define uma posição contrária à tese de que a percepção seria uma reação sensorial aos estímulos recebidos do meio.

\section{Percepção Espacial e decorrências fenomenológi- cas}

As ideias trabalhadas por Husserl em 1907 convergiram, direta ou indiretamente, no desenvolvimento de teorias psicológicas sobre a percepção espacial. Três importantes representantes desta convergência temática são David Katz (1884-1953), James J. Gibson (1904-1979), e o filósofo contemporâneo Alva Noë, um professor da Universidade da Califórnia, Berkeley, interessado em percepção e consciência. A seguir, destaca-se como a teoria fenomenológica da percepção espacial se relaciona ao trabalho destes três pesquisadores, representando o desenvolvimento durante o século XX.

A repercussão mais direta pode ser observada nos estudos do psicólogo experimental alemão que foi orientado por Georg Elias Müller no período das conferências de Husserl em Göttingen. Em 1911, David Katz escreve seu principal trabalho sobre a percepção das cores a partir de estudos experimentais, dando destaque à função da intencionalidade na constituição da espacialidade, em oposição às teses da sensação na tradição de Hermann von Helmholtz (1821-1894). O livro foi traduzido para o inglês em 1935, com reimpressões em 1970, 1999, 2000, 2001, 2002 o que aponta para a importância da obra. Na apresentação de sua teoria da percepção das cores, Katz (1911/1935) mencionou Ewald Hering (1834-1918) como principal influência, informando que as ideias de Husserl sobre esse tema não eram tão inéditas ao tempo das conferências de Göttingen. Para Katz (1943/1945), o padrão de percepção das cores poderia servir de exemplo para a percepção do espaço como um todo. Para tanto, seria necessário levar em conta que a percepção de uma cor não se limita à correlação estímulo-percepção, segundo as variações unidimensionais de intensidade. Requer ainda a investigação de covariantes de iluminação nos objetos que circundam o espaço da percepção. Ou seja, a percepção de espaço é o produto da posição espacial do sujeito em relação ao contexto percebido, bem como as relações de iluminação e sombra entre os objetos que compõem o cenário da percepção total. Posteriormente, algumas das teses de Katz foram trabalhadas por Köhler na questão dos padrões da continuidade perceptiva da visão (Ash, 1995). Katz reconheceu a grande influência de Husserl para suas pesquisas experimentais, em particular, a atitude fenomenológica nas seguintes palavras:

Para mim, a fenomenologia como advogada naquele tempo (i.e. durante os anos de estudante de Katz em Göttingen) por Edmund Husserl, parece ser a mais importante conexão entre filosofia e psicologia. Nenhum dos meus professores acadêmicos, com exceção de G. E. Müller, influenciou-me tão profundamente no procedimento e na atitude sobre as questões psicológicas quanto Husserl com seu método fenomenológico. (Katz, 1952 citado por Spiegelberg, 1972, p. 44). 
A constituição da percepção visual reaparece fortemente nos meados do século XX com a profícua produção do pesquisador norte-americano James J. Gibson (1904-1979). Em especial seu livro de 1979, intitulado The ecological approach to visual perception, que aborda a construção da percepção e propriocepção a partir do uso ativo que o organismo faz dos recursos disponíveis em seu meio. A relação de Gibson com a fenomenologia é indireta, sendo apenas possível realizar indicações de convergência conceitual e temática entre as ideias sobre percepção de movimento e propriocepção.

Para Gibson (1979), a conexão ecológica é princípio e não fim para entender a emergência da percepção. Seu conceito mais conhecido é affordance, que tange especificamente sobre este uso intencional dos recursos ambientais para situar a percepção visual em uma articulação ativa com o meio. Segundo Gibson (2002), a percepção visual deve ser estudada e entendida como um processo direto no ambiente, sem recorrer às teses de processamento indireto ou representação da visão total como imagem no córtex occipital. Acerca dessa defesa, Gibson afirma que o sistema visual estrito faz uma seleção de estímulos no meio antes de qualquer mediação de filtro sensorial secundário no cérebro. Isto significa afirmar que os olhos têm capacidade suficiente de seleção de estímulos, levados por uma intenção prévia, sem que seja necessária uma captação da imagem total para posterior reorganização topográfica dos estímulos em um córtex específico.

Mais recentemente encontra-se em Nöe (2004) um retorno às teses de Katz e Gibson para examinar, por meio de estudos experimentais, a relação entre intencionalidade pré-consciente e reorganização intencional, conforme a discriminação de pistas ambientais durante o desempenho da ação. Para Nöe, a ação no meio constitui a percepção, sendo que as subsequentes atualizações interferem continuadamente nas intenções da ação. Observa-se novamente, nesse exemplo, que o conceito de intencionalidade é ressignificado à luz das ações efetivas do organismo no ambiente, até como uma intencionalidade operante. Contudo, a mediação autoconsciente não é ponto chave aqui para a constituição intencional, como desponta no texto de 1907 de Husserl. Nöe recorreu a vários estudos de Gibson para afirmar a tese de que a percepção recairia, em ultima instância, sobre a ação corporal no ambiente. Nesse sentido, não seria nem uma criação autoconsciente nem uma dependência pura de contingências ambientais. Trata-se de uma combinação entre realismo e idealismo. Aliás, a tese sobre a ação no meio não descarta o modelo funcional de seleção por consequências, mas retoma a importância enativa do organismo nas trocas com este meio e o papel da autoconsciência nessa mediação. Por enativa entende-se a ação guiada pela percepção na vivência sensório-motora contextualizada do sujeito da ação (Varela, Thompson \& Rosch, 1991).
As pesquisas sobre percepção visual desenvolvidas por Katz (1911/1935), Gibson (1979) e Noë (2004) abordam, em certa medida, a relação entre intencionalidade e concomitância autoconsciente na ação, considerando as interferências da mediação pré-consciente e intenção motora dos atos. Nesse sentido, qual seria a relação entre motricidade, consciência dos atos e intencionalidade? Tal questão é pertinente diante do entendimento de que as atualizações entre o encontro da intencionalidade com as contingências ambientais provocam um momento de retomada unitária da experiência do corpo.

A discussão emergente desses novos desenvolvimentos da fenomenologia está nas questões decorrentes de como compreender e explicar as atualizações constantes e operantes da percepção espacial e da propriocepção. O ponto chave nessa discussão procede das ciências cognitivas de abordagem enativa (Thompson, 2007), sob o argumento de que tais atualizações do comportamento e da percepção não dependem exclusivamente de pistas ambientais, mas especialmente da intencionalidade prévia em relação ao ambiente. Para essa ciência cognitiva influenciada pela fenomenologia, existiria um modo intencional operante que caracteriza os modos de acesso perceptivo às coisas e que não exclui os elementos contingenciais reais do ambiente (Smith, 1999). Nesse sentido, reafirma-se, mais uma vez, não se tratar nem de um idealismo puro e nem de um realismo puro. Haveria, portanto, modos intencionais tipificados que acessam o meio de forma ativa ou operante, mas que se atualizam permanentemente conforme as pistas ambientais para se reorganizar. Nesse momento de reorganização, a retomada autoconsciente da experiência seria fundamental para a preparação intencional a experiências futuras.

\section{4. “Quem sou eu?" - Transições da fenomenologia para experimentação}

Em uma tentativa de reunir a fenomenologia constitutiva husserliana e a neurocognição, os atos pré-conscientes vêm sendo estudados em experimentos que incluem a descrição experiencial consciente após o desempenho de determinadas tarefas (Lutz \& Thompson, 2003). Os experimentos consistem na proposição de uma tarefa experiencial e motora, passível de ser descrita, com objetivo de verificar a associação entre a descrição perceptiva e o desempenho corporal (motor). Pesquisas em neurociência (Iriki, Tanaka \& Iwamura, 1996) desde meados da década de 1990, têm demonstrado que o uso de ferramentas como prolongamento do corpo intencional coincide com os achados sobre a ativação de neurônios viso-táteis na utilização de instrumentos por macacos.

Em relação aos achados neurocientíficos sobre a função integrada de visão e tato em um mesmo neurônio, cabe uma ressalva ao texto husserliano. Para Husserl (1907/1997), os sistemas sensórios eram correlacionados 
e complementares, uma idéia desafiadora para os sistemas teóricos atomistas de seu tempo. Contudo, Husserl não entra no mérito da questão neurológica, pois não quer recair nas propostas biológicas da consciência ou da causalidade psíquica. Ele enfatiza a necessidade de se manter no âmbito puro descritivo da experiência de sensação de movimentos. Atualmente, o que se constata é que não apenas os sistemas cerebrais estão correlacionados, como também residem, em uma unidade cerebral, diferentes funções concomitantes, como atividade motora, cognitiva e respostas sensórias efetoras.

Ainda em Husserl, a doação de significado para a experiência do corpo aparece implicada a uma concepção de plasticidade dos movimentos, que requerem constantes atualizações, e ao uso de ferramentas para o acesso intencional do mundo. A formação da espacialidade passa em 1907 pela articulação autorreferente dos atos corporais em uma experiência consciente estendida no tempo. É impossível neste ponto não associar a posição de Husserl com o verbete de percepção espacial na Enciclopédia de Ciências Cognitivas do MIT (Colby, 1999, p. 786): "Nossa experiência unitária do espaço emerge de uma diversidade de representações espaciais estendidas no tempo”. A semelhança entre a fenomenologia do espaço e a recente ciência cognitiva é realmente inegável.

O tema da vigília autoconsciente na sensação de movimentos do próprio corpo ganha contornos mais complexos quando se contrastam as definições de Husserl com a definição contemporânea de cinestesia. Henrik H. Ehrsson, um aclamado neurocientista cognitivo de Estocolmo, escolheu, para sua conferência proferida no Congresso Toward a Science of Consciousness realizado em Tucson/AZ nos EUA, o título: "Two legs, two arms, one head: Who am I?" (Ehrsson, 2010). O confronto entre as duas pernas, os dois braços e uma cabeça remete exatamente ao problema da presença da autoconsciência no desempenho e na percepção de atos motores. Ehrsson investiga as relações entre percepção e comportamento com base em pesquisas com ilusão corpórea. Seus estudos articulam dados de correlato neural e descrição de experiência dos participantes em um contexto de tarefa experimental. O pesquisador defende a tese de integração dos sistemas sensoriais e, por conseguinte, integração de áreas cerebrais na constituição da percepção do espaço. Os trabalhos de Ehrsson levantam, em alguma medida, a indagação sobre a importância da mediação da consciência reflexiva no desempenho motor e perceptivo em situações de ambiguidade proprioceptiva. Isto é, qual o nível de influência da autorreflexividade implícita necessária para o desempenho de ações. Nessa direção, discute o tema da intencionalidade do organismo em seus experimentos. A incerteza e principalmente instabilidade sobre a experiência integrada e unitária do corpo, como revelados por seus achados experimentais, levam Ehrsson a perguntar: Quem sou eu?

O pesquisador sueco representa uma linha de pesquisa que tem procurado compreender a conexão entre traços psicológicos e as variações na sensação de movimento (cinestesia). Mais especificamente, a relação entre ação, autoconsciência e intencionalidade motora. Nessas pesquisas criam-se ambientes de ação em que se geram ambiguidades perceptivas para o acompanhamento dos processos decisórios motores e autoconscientes associados à tomada de posição diante das ambiguidades. Tais ambiguidades baseiam-se, em grande parte, na perturbação da integração de canais sensoriais.

Um exemplo de estudo é o experimento conhecido como Rubber Hand Illusion (RHI), que busca avaliar a integração intermodal proprioceptiva na auto-atribuição de membros fantasmas (Botvinick \& Cohen, 1998). Os pesquisadores criam uma situação de ilusão perceptiva em que se produz uma distorção da posição manual pela estimulação sincrônica de uma mão verdadeira e uma mão de borracha. A partir de uma variação de condições experimentais Ehrsson, Spence, e Passinham (2004) evidenciaram que a ocorrência da ilusão na tarefa RHI depende de uma estimulação sincrônica da mão verdadeira e da mão falsa. Em média, 80\% dos participantes relatam a ilusão esperada pela indução da RHI, dentro de um intervalo de 15 segundos de estimulação sincrônica na mão verdadeira e na mão de borracha (Ehrsson, Holmes \& Passingham, 2005). Embora a sincronicidade viso-tátil da estimulação seja um fator importante na produção da ilusão, não é suficiente para explicar a recalibração proprioceptiva. Tsakiris e Haggard (2005) demonstraram que o efeito da ilusão diminui ou se extingue mesmo com estimulação em sincronia, quando a postura ou a lateralidade da mão de borracha são incongruentes com a posição da mão verdadeira. Essa evidência indica que representações e expectativas prévias sobre o corpo exercem também um importante papel na propriocepção.

Sobre a integração dos canais sensoriais na percepção, Ehrsson, Holmes e Passingham (2005) demonstraram que o aumento sensível da atividade nos córtices pré-motor, ventral intra-parietal bilateral e cerebelo correspondem ao aumento gradual da intensidade da ambiguidade ou ilusão perceptiva gerada nos contextos de tarefa. Isso comprova que diferentes regiões do cérebro estão altamente integradas na percepção e que não haveria uma prevalência de um canal sensório sobre o outro na integração perceptiva. Ou seja, já partindo das constatações de que a percepção está integrada, tanto na cinestesia quanto na propriocepção conceitual e unitária do corpo, busca-se avaliar a reação do corpo diante da dissociação da integração perceptiva.

As perguntas lançadas remetem aos comportamentos observados no laboratório. Isto é, diante de ambiguidades perceptivas prevalece o padrão intencional motor previamente aferido, independente da distorção? Ou prevalece o ajuste da ação de acordo com a mediação autoconsciente da dissociação perceptiva durante o ato? Tais achados sobre plasticidade da atualização proprioceptiva podem auxiliar no tratamento ou reabilitação individualizada de sujeitos, que por alguma razão possuam prejuízo na in- 
tegração proprioceptiva do corpo (ex. amputados, comorbidades de auto-imagem em transtornos alimentares, ou mesmo esquizofrenia). Essas perguntas estão sendo investigadas no Laboratório de Fenomenologia Experimental e Cognição da UFRGS, através de dois paradigmas experimentais de ilusão perceptiva em tarefas experimentais com seres humanos.

\section{Considerações Finais}

De modo direto ou indireto, a problemática da concomitância autoconsciente na percepção de movimentos sustenta o mesmo interesse teórico levantado por Husserl há mais de um século atrás. A pergunta continua sendo a mesma: como se constitui e se desenvolve a percepção? Embora os caminhos de investigação tenham seguido por rumos diferentes, as nuanças da percepção continuam a despertar interesse, como bem atestam os estudos recentes do pesquisador H.H. Ehrsson. As divergências entre Husserl e os psicólogos experimentais da época, representados por Müller, foram captadas com elegância pelo psicometrista C. E. Spearman, em sua autobiografia, referindo-se à visita que fez à Universidade de Göttingen em 1906. Spearman discorreu sobre Husserl, após descrever suas impressões das aulas de Müller:

Na mesma universidade, a de Göttingen, eu tive a vantagem adicional de assistir as palestras de Husserl, em seu modo, um grande homem como G.E. Müller. Mas rumos seguidos por eles os levaram a mundos à parte. Na verdade, a única coisa que parecia comum aos dois era a inabilidade de um apreciar o outro! Para Müller, as análises refinadas de Husserl pareciam ser um renascimento da idade média (como, de fato, elas amplamente foram, mas não necessariamente como uma desvantagem). Para Husserl, as tentativas de Müller em lidar com os problemas psicológicos por meio de experimentação era como tentar desvendar rendas com um tridente. Ainda assim, o procedimento de Husserl - como ele o descreveu para mim - apenas diferia daquele usado pelo melhor experimentalista, lidando com problemas similares, em que pesa Husserl não ter ninguém além dele mesmo como sujeito experimental (Spearman, 1930 citado por Spiegelberg, 1972, p. 35).

Mesmo trabalhando com problemas similares, como atesta Spearman na citação, Husserl mantinha uma forte preocupação em definir um programa filosófico sólido o suficiente para se afastar das proposições empíricas embasadas em um tipo de racionalismo que ele discordava. O projeto que Husserl seguiu foi o de uma filosofia primeira como refundação para as ciências naturais. Nesse sentido, seu desentendimento praticamente generalizado com a psicologia empírica da época pode ser compreendido a partir do panorama dessa refundação.
O tipo de confronto entre apologistas e detratores da ciência natural parece ser reeditado de tempos em tempos, especialmente sob o argumento da distinção entre ciências humanas e ciências naturais. Tal discussão não escapa à literatura fenomenológica. Contudo, com os avanços tecnológicos e a incorporação da descrição de experiência como heurística em protocolos experimentais, tal distinção parece perder espaço para o debate mais profícuo em torno dos acréscimos que uma teoria pode sugerir a outra. Este novo horizonte também se situa na revisão da definição clássica de naturalismo, que vem sendo ressignificada pelas mudanças recentes na investigação científica (Zahavi, 2009).

\section{Referências}

Ash, M. G. (1998). Gestalt Psychology in German Culture, 1890-1967: Holism and the quest for objectivity. New York: Cambridge University Press.

Botvinick, M., \& Cohen, J. (1998). Rubber hands 'feel' touch that eyes see. Nature, 391, 756.

Cardinali, L., Brozzoli, C., \& Farnè, A. (2009). Peripersonal space and body schema: two labels for the same concept? Brain Topography, 21, 252-260.

Colby, C. L. (1999). Spatial Perception. Em R. A. Wilson \& F. C. Keil (Eds.), The MIT Encyclopedia of the Cognitive Sciences (pp. 784-787). Cambridge, MA: The MIT Press.

Ehrsson, H. H. (2010). Two legs, two arms, one head. Who am I? [Resumo]. Em Toward a Science of Consciousness (Org.), Program and Book of Abstracts, Tucson IX Toward a Science of Consciousness (p. 115). Tucson, AZ: TSC.

Ehrsson, H. H., Spence, C., \& Passingham, R. E. (2004). That's my hand! Activity in premotor cortex reflects feeling of ownership of a limb. Science, 305, 875- 877.

Ehrsson, H. H., Holmes, N. P., \& Passingham, R. E. (2005). Touching a rubber hand: Feeling of body ownership is associated with activity in multisensory brain areas. Journal of Neuroscience, 25, 10564-10573.

Gibson, J. J. (2002). A theory of direct visual perception. Em A. Nöe, \& E. Thompson (Eds.), Vision and Mind: selected readings in the philosophy of perception [pp. 77-90]. Cambridge, MA: The MIT Press.

Gibson, J. J. (1979). The ecological approach to visual perception. Hillsdale, NJ: Lawrence Erlbaum Associates - LEA - Publishers.

Hubbard, E. M., \& Ramachandran, V. S. (2005). Neurocognitive mechanisms of synesthesia. Neuron, 48(3), 509-520.

Husserl, E. (1977). Phenomenological Psychology: Lectures, summer semester 1925. The Hague: Martinus Nijhoff.

Husserl, E. (1997). Thing and Space: Lectures of 1907. Netherlands: Kluwer Academic Publisher. 
Husserl, E. (2000). A idéia da fenomenologia. Lisboa: Edições 70. (Original publicado em 1907).

Husserl, E. (2006). Idéias para uma fenomenologia pura e para uma filosofia fenomenológica. São Paulo: Idéias \& Letras (Original publicado em 1913).

Iriki, A.; Tanaka, M. \& Iwamura, Y. (1996). Coding of modified body schema during tool use by macaque postcentral neurones. NeuroReport, 7, 2325-2330.

Katz, D. (1935). The world of colour (R. B. Macleod \& C. W. Fox, Trad). London: Kegan Paul Trench, \& Truebner (Original publicado em alemão, 1911).

Katz, D. (1945). Psicología de la forma (J.M. Sacristán, Trad.). Madrid: Espasa-Calpe, S.A. (Original publicado em 1943).

Klein, D. B. (1970). A history of scientific psychology. New York: Basic Books

Lutz, A., \& Thompson, E. (2003). Neurophenomenology: Integrating subjective experience and brain dynamics in the neuroscience of consciousness. Journal of Consciousness Studies, 10 (9-10), 31-52.

Noë, A. (2004). Action in Perception. Boston, MA: The MIT Press.

Petit, J-L. (2010). A husserliana, neurophenomenologic approach to embodiment. Em S. Gallagher \& D. Schmicking (Eds.), Handbook of Phenomenology and Cognitive Sciences [pp. 201-216]. New York: Springer.

Schmicking, D. (2010). A toolbox of phenomenological methods. Em S. Gallagher \& D. Schmicking (Eds.), Handbook of Phenomenology and Cognitive Sciences [pp. 35-56]. New York: Springer.

Smith, D. W. (1999). Intentionality naturalized? Em J. Petitot, F. J. Varela, B. Pachoud, \& J-M. Roy (Eds.), Naturalizing phenomenology: issues in contemporary phenomenology and cognitive science [pp. 83-110]. Stanford, CA: Stanford University Press.
Spiegelberg, H. (1972). Phenomenology in Psychology and Psychiatry: a historical introduction. Evanston: Northwestern University Press.

Thompson, E. (2007). Mind in life: Biology, phenomenology and the sciences of mind. Cambridge, MA: Harvard University Press.

Tsakiris, M., \& Haggard, P. (2005). The rubber hand illusion revisited: visuotactile integration and self-attribution. Journal of Experimental Psychology: Human Perception and Performance, 39(1), 80-91.

Varela, F.J., Thompson, E., \& Rosch, E. (1991). The Embodied Mind: cognitive science and human experience. Cambridge, MA: MIT Press.

Zahavi, D. (2009). Naturalized Phenomenology. In S. Gallagher and D. Schmicking (eds.), Handbook of Phenomenology and Cognitive Science (pp. 1-12). Netherlands: Springer.

Thiago Gomes de Castro - Mestre em Psicologia (UFRGS) e Doutorando no Programa de Pós-Graduação em Psicologia da UFRGS. Pesquisador do Laboratório de Fenomenologia Experimental e Cognição - LaFEC. Endereço Institucional: IP/UFRGS, Rua Ramiro Barcelos, 2600 - Sala 123. CEP 90035.003. Porto Alegre/RS. E-mail: thiago.cast@gmail.com

William Barbosa Gomes - PhD em Psicologia pela Southern Illinois University e com estágios de pós-doutoramento na Southern Illinois University e na Universidade de Michigan, fundador e professor do Programa de Pós-Graduação em Psicologia da UFRGS. Coordenador do Laboratório de Fenomenologia Experimental e Cognição - LaFEC. Endereço Institucional: IP/UFRGS, Rua Ramiro Barcelos, 2600 - Sala 123. CEP 90035.003. Porto Alegre/RS. E-mail: gomesw@ufrgs.br

Recebido em 16.06.2011 Aceito em 23.09.11 